\title{
Low-density lipoprotein cholesterol to apolipoprotein B ratio is associated with all-cause mortality and cardiovascular events among incident peritoneal dialysis patients
}

\section{Xiaojiang Zhan ( $\nabla$ zhanxiaogang87@163.com )}

The First Affiliated Hospital of Nanchang University

Chuanfei Zeng

Nanchang University

Qing Zhan

Nanchang University

\section{Xiqi Dong}

Nanchang University

\section{Yanbing Chen}

The First Affiliated Hospital of Nanchang University

\section{Research Article}

Keywords: Low-density lipoprotein cholesterol, Apolipoprotein B, All-cause mortality, Cardiovascular event, Peritoneal dialysis

Posted Date: February 9th, 2022

DOI: https://doi.org/10.21203/rs.3.rs-1334091/v1

License: (c) (i) This work is licensed under a Creative Commons Attribution 4.0 International License.

Read Full License 


\section{Abstract}

Background: The ratio of low-density lipoprotein cholesterol (LDL-C)/apolipoprotein B (apo B) is associated with all-cause mortality and cardiovascular events in chronic kidney disease patients. The aim of this study was to investigate the association between the LDL-C/apo B ratio (LAR) and all-cause mortality and cardiovascular events in peritoneal dialysis (PD) patients.

Methods: A total of 1199 incident PD patients were enrolled from November 1, 2005 to August 31, 2019. The LAR was used to divide the patients into two groups by X-Tile software and restricted cubic splines using 1.04 as the cutoff. The incidence of all-cause mortality and cardiovascular events at follow-up was compared according to LAR.

Results: Of the 1199 patients, $58.0 \%$ were men, the mean age was $49.3 \pm 14.5$ years, 225 patients had a history of diabetes, and 117 patients had prior cardiovascular disease. During the follow-up period, 326 patients died, and 178 patients experienced cardiovascular events. After full adjustment, a low LAR was significantly associated with HRs for all-cause mortality of $1.40(95 \% \mathrm{Cl}: 1.04$ to $1.87, \mathrm{P}=0.040)$ and for cardiovascular events of 1.62 (95\% Cl: 1.11 to $2.38, \mathrm{P}=0.008)$.

Conclusions: This study suggests that a low LAR is an independent risk factor for all-cause mortality and cardiovascular events in PD patients, indicating that the LAR may provide significant information when assessing all-cause mortality and cardiovascular risks.

\section{Background}

Peritoneal dialysis (PD) is a renal replacement therapy used among approximately $11 \%$ of global patients undergoing long-term dialysis[1, 2]. The adjusted all-cause mortality of PD patients decreased from 164.2 per 1,000 person-years in 2009 to 131.5 per 1,000 person-years in 2018 and in 2004-2014, their mortality in the first year after beginning PD decreased from 163.4 to 107.7[3]. However, the long-term mortality of PD patients has always been one of the important factors restricting the application of PD[4-6]. Cardiovascular disease (CVD) is a serious complication of PD and causes of $60 \%$ deaths in this population[7]. The increased risk of morbidity and mortality associated with CVD in patients on PD is at least partially due to lipid abnormalities known as uremic dyslipidemia[8]. One study showed that approximately $50 \%$ of PD patients with abnormalities of atherogenic lipoprotein had an increased risk for the development of CVD[9]. However, there are no clear indicators to predict all-cause mortality and cardiovascular events in patients with PD, and the specific mechanism is unclear and needs to be resolved.

Low-density lipoprotein (LDL) is a lipoprotein particle approximately 19-22 nm in diameter with an average density of $1.019-1.063 \mathrm{~g} / \mathrm{mL}$ that can transport fat molecules within the body[10]. Some studies show that LDLs are the major cholesterol-transporting lipoproteins in plasma, and LDL cholesterol (LDLC) is recognized as the major atherogenic lipoprotein cholesterol[11, 12]. The atherogenic risk depends not only on the amount of LDL-C but also on the number and size of the LDL particles[13]. Studies have 
shown that more intensive LDL-C lowering was associated with reductions in total and cardiovascular mortality[14]. In addition, LDL-C is considered to be an independent risk factor for CVD in chronic kidney disease (CKD), which is the most important cause of death in dialysis patients[15]. However, there is a qualitative difference in LDL-C between PD patients and normal controls because of the increased concentration of small and dense particles along with high apolipoprotein $B($ apo $B)[16,17]$. LDL-C/apo $B$ (LAR) can be used as an index to predict all-cause mortality and cardiovascular events in patients with nonrenal diseases. As LDL-C can carry only a single apo B, the LAR can serve as a tool to estimate the LDL particle size[18, 19]. Drexel $\mathrm{H}$ et al. showed that the LAR could independently predict major cardiovascular events in subjects with established atherosclerosis[20]. In addition, LAR has also been shown to be closely associated with metabolic syndrome, coronary heart risk score, neointimal hyperplasia and intimal instability in nonrenal diseases[21-23].

However, the predictive value of the LAR in understanding all-cause mortality and cardiovascular events in PD patients remains unclear. Therefore, the present study was conducted to investigate the impact of LAR levels on predicting all-cause mortality and cardiovascular events among PD patients.

\section{Methods}

\section{Study population and design}

A total of 1457 patients who visited the PD Center of the First Affiliated Hospital of Nanchang University, Jiangxi Province for PD renal replacement therapy from November 1st, 2005 to August 31st, 2019 were enrolled. All PD patients were followed up until PD cessation, switched to hemodialysis, kidney transplantation, transferred to another center, refused additional treatment, died, or were lost to follow-up or December 31, 2020, whichever came first. The inclusion criteria for the study were older than 18 years old and a dialysis age of at least three months. The exclusion criteria were age younger than 18 years old, failure of hemodialysis or renal transplantation, cessation of peritoneal dialysis within the first three months, lack of LDL-C or Apo B data, and known malignant tumors. Finally, 1199 patients were included in the study, excluding 15 cases under 18 years old, 8 cases of hemodialysis, 4 cases of failed renal transplantation, 25 cases of dialysis time less than 3 months, 7 cases of malignant tumor and 199 cases without detection of LDL-C or apo B (Figure 1).

This study selected the best cutoff value of LAR (Group $1<1.04$ and Group $2 \geq 1.04$ ) by the X-tile procedure (Yale University, New Haven, CT, USA) [24], which is an important tool for outcome-based cutoff point optimization and restricted cubic splines. The association between LAR and all-cause mortality and cardiovascular events was analyzed by using the Cox proportional risk model. Model 1 was adjusted for age, sex, body mass index (BMI), estimated glomerular filtration rate (eGFR), Charlson Comorbidity Index (CCI), diabetes, hypertension, and premorbid CVD. Model 2 was further adjusted for hemoglobin, albumin, alkaline phosphatase, phosphorus, intact parathyroid hormone (iPTH) and ferritin. Model 3 was further adjusted for high-density lipoprotein cholesterol, triglyceride (TG), and lipid-lowering medication. This 
study was approved by the Human Ethics Committee of Nanchang University (Application ID: [2021] 9028).

\section{Baseline data}

The characteristics and biochemical data of all PD patients included age, sex, BMI, CCl, prediabetes, hypertension, pre-CVD, eGFR, hemoglobin, albumin, total cholesterol (TC), TG, HDL-C, LDL-C, apo B, phosphorus, iPTH and ferritin. Immunoturbidimetry was used to detect serum apo B[25]. Serum HDL-C, LDL-C, and TG concentrations were measured by enzymatic methods[23, 26].

\section{Definition of cardiovascular events}

According to the guidelines and related literature[27, 28], this study defined cardiovascular events in patients as follows: myocardial infarction, angina pectoris, heart failure, cerebral infarction, cerebral hemorrhage, peripheral vascular events, aneurysm dissection or ruptured death, other (metabolic cardiomyopathy, Adams-Stokes syndrome, arrhythmia) or unexplained death.

\section{Statistical analyses}

SPSS version 22.0 (SPSS, Inc., Chicago, IL) was used for statistical analysis, and R version 3.6.0 (http://www.r-project.org) was used for survival analysis. The t-test, Chi-square test, and Kruskal-Wallis test were used to test for differences between the LAR groups. Frequencies and percentages are presented for categorical variables, medians and interquartile ranges are presented for nonnormally distributed data, and means and standard deviations (SDs) are presented for normally distributed data. $\mathrm{P}$ $<0.05$ represents statistical significance.

\section{Results}

\section{Baseline characteristics}

A total of 1199 subjects, including 696 men and 503 women, were included: the mean \pm SD age was 49.3 \pm 14.5 years, 225 patients had a history of diabetes, and 117 patients had prior CVD in this study. During the 35-month (interquartile range=20-57 months) follow-up period, 326 patients died, and 178 patients experienced CV events (Figure 1). The baseline characteristics of all patients are shown in Table 1. Age, sex, hypertension, CVD, albumin, TC, TG, LDL-C, HDL-C, Apo B, and ferritin were significantly different $(\mathrm{P}<$ 0.05). No significant differences among body mass index, diabetes, eGFR, hemoglobin, phosphorus or iPTH were observed (Table 1). In addition, PD patients with a low LAR were older and had less hypertension; decreased levels of albumin, TC, HDL-C, and LDL-C; and increased levels of TG, apo B and ferritin $(P<0.05)$. 


\section{The correlations among LAR, all-cause mortality, and cardiovascular events}

At the end of the follow-up, the cumulative survival rate of all patients in the low LAR group decreased significantly according to the Kaplan-Meier analysis $(P<0.0001$, Figure $2 A)$. Similarly, the cumulative rate of cardiovascular events increased significantly $(P<0.0001$, Figure $2 B)$. Using Cox regression analysis, we determined the association between the LAR and all-cause mortality and cardiovascular events, as shown in Table 2. There were significant differences in the association between LAR and all-cause mortality and cardiovascular events in Models 1, 2 and 3. In Model 3, the HRs and 95\% Cls for LAR $<1.04$ versus LAR $\geq 1.04$ were $\mathrm{HR}, 1.40$ (95\% Cl: 1.04 to 1.87 ), and $\mathrm{HR}, 1.62$ (95\% Cl: 1.11 to 2.38 ), for all-cause mortality and cardiovascular events, respectively. In addition, the restricted cubic splines showed that the risk of allcause mortality and cardiovascular events decreased gradually when the LAR was $>1.04$ (Figure 3 ).

\section{Discussion}

In this study, we found that LAR was associated with all-cause mortality and cardiovascular events in PD patients. PD patients with low LAR were older, had less hypertension; decreased levels of albumin, TC, HDL-C, and LDL-C; and increased levels of TG, apo B and ferritin. Moreover, low LAR patients had higher all-cause mortality and cardiovascular events. Therefore, the LAR can be used as a significant important risk indicator for PD patients.

$P D$ is an effective renal replacement therapy for patients with advanced CKD. However, dyslipidemia is common in PD patients. Patients with advanced CKD are characterized by increased levels of TG, mainly due to decreased lipolysis of TG-rich lipoproteins, accompanied by lower levels of HDL-C[29, 30].

These dyslipidemias are present in patients with advanced CKD and in CKD patients treated with PD[31, 32]. The main manifestation is a decrease in HDL, HDL-C and HDL-2/HDL-3 and an increase in TC, intermediate-density lipoprotein, chylomicron remnants, HDL triglyceride, LDL triglyceride, and lipoprotein lipase activity[32].

LDL-C is a strong predictor of coronary heart disease. Decreasing LDL-C levels is considered to be the main therapeutic target for the treatment of hypercholesterolemia and this approach can reduce the incidence of major atherosclerotic events in patients with advanced CKD [33, 34]. Related studies have shown that reducing serum LDL-C levels can effectively reduce the risk of ischemic stroke, myocardial infarction and coronary artery death[35]. Massy ZA et al. have shown that half of CKD patients have an LDL-C that exceeds the recommended target, and a significant proportion do not receive treatment, thus increasing the morbidity and mortality of CKD patients due to coronary heart disease and stroke[36]. However, other studies have found that there is no significant correlation between the level of LDL-C and the prognosis of atherosclerotic CVD in CKD[37]. Tani S et al. found that a low LDL-C level in patients with coronary artery disease and advanced kidney disease was associated with a poor prognosis[38]. Our study showed that after adjusting for age, sex, BMI, eGFR, CCl, diabetes, hypertension, premorbid CVD, hemoglobin, albumin, alkaline phosphatase, phosphorus, iPTH, ferritin, HDL-C, TC, and lipid-lowering 
medication, the LDL-C levels were not significantly associated with all-cause mortality or cardiovascular events. Therefore, further research is required to resolve this controversy.

Apo $B$ is the main structural lipoprotein of $L D L, V L D L$, medium density lipoprotein and lipoprotein $A$. Each particle has one apo $B$, so the measurement of apo $B$ is used to determine the exact number of atherogenic lipoprotein particles[18, 39]. The trapping of apo B lipoprotein particles within the arterial wall plays an important role in initiating and driving the atherosclerotic process[40]. A study found that low apo B levels may be an effective marker of left ventricular hypertrophy in PD patients [41]. In addition, other studies have shown that apo B levels are higher in PD patients than in hemodialysis and normal subjects and that a high apo $B$ level increases the risk of coronary heart disease in PD patients[42]. Current evidence suggests that apo B measures the risk of atherosclerosis caused by apolipoprotein more accurately than LDL-C or non-HDL-C [43]. However, the predictive ability of apolipoprotein $B$ is not always better than that of non-HDL-C. Di Angelantonio E [44] and Benn M [45] showed that non-HDL-C and apo B have the same predictive ability. A cross-sectional study showed that higher apo $B$ is associated with the prevalence of coronary heart disease[46]. Lamprea-Montealegre JA et al. showed that higher apo B is associated with an increased risk of atherosclerotic vascular events in patients with CKD[47]. In the fully adjusted model, apo B was positively correlated with CVD-related mortality[48]. However, our study showed that apo B was not significantly associated with all-cause mortality or cardiovascular events.

LDL particles can be divided into large and low-density LDL particles (diameter $>25 \mathrm{~nm}$ ) and small and dense LDL (diameter <25 nm) $[49,50]$. Small and dense low-density lipoprotein particles have higher arterial wall permeability, lower LDL receptor binding affinity, a longer plasma half-life and lower oxidative stress resistance[11, 51-53]. St-Pierre AC et al. showed that in patients with LDL particle sizes of 25.5 $\mathrm{nm}$ or smaller, the incidence of coronary heart disease increased significantly with increasing serum LDL$C$ levels[54]. Similarly, some patients may have the same LDL-C level, but patients may have more or smaller LDL particles, and their risk may be higher[55]. The LAR indirectly determines the size of the LDL particles. Some studies have shown that the LAR can distinguish between large loose LDL and small dense LDL, and the latter leads to a significant increase in the incidence of coronary heart disease[56-58]. Therefore, LAR is an independent predictor of coronary heart disease $[13,59,60]$. Rabizadeh $S$ et al. showed that LAR $\leq 1.2$ can independently predict coronary heart disease[23]. Bae JC et al. used LAR as an alternative indicator of LDL particle size and found that LAR had a significant negative correlation with the incidence of CKD, especially when LAR $\leq 1.29$ [61]. Tani et al. showed that in male patients treated with statins, the LAR in patients with coronary heart disease was significantly lower [19]. This finding is similar to our findings, which show that all-cause mortality and cardiovascular events increased significantly when $L A R<1.04$. The reason may be that low LAR is mainly characterized by small and dense LDL particles. Since each particle can only contain one apo $B$, an increase in serum apo $B$ may indicate that there are a large number of LDL particles in the blood circulation, thus increasing the risk of cardiovascular events. This has been confirmed in several studies[56, 57, 62]. Previous studies have shown that the level of plasma apo B-cholesterol may better reflect the number of atherogenic granules than the concentration of LDL-C[63]. Although our study shows that apo B levels alone do not predict all- 
cause mortality and cardiovascular events, as an alternative to LDL-C particle size alone, a lower LAR in PD patients may play an important role in predicting all-cause mortality and cardiovascular events.

Our study also has some limitations. For example, this is a retrospective study with a small sample size, followed by no assessment of the effects of inflammatory cells and inflammatory factors, as well as the impact of some unknown factors on blood lipid levels in PD patients. Although lipid-lowering drugs were adjusted in the risk model, this factor was not taken into account in the grouping of LAR, indicating improvements are necessary in future studies.

\section{Conclusion}

In summary, LAR can be used as a new risk marker for all-cause mortality and cardiovascular events in patients with PD. Low LAR is associated with higher all-cause mortality and cardiovascular events, along with increased age; decreased levels of albumin, TC, HDL-C, and LDL-C; and increased levels of TG, apo B and ferritin.

\section{Abbreviations}

PD, Peritoneal dialysis; LDL-C, low-density lipoprotein cholesterol; Apo B, apolipoprotein B; BMI, Body mass index; $\mathrm{CCl}$, Charlson Comorbidity Index; eGFR, estimated glomerular filtration rate; CVD, cardiovascular disease; CKD, chronic kidney disease; HDL-C, high-density lipoprotein cholesterol; iPTH, intact parathyroid hormone; TG, Triglyceride; TC, Total cholesterol; LAR, LDL-C to ApoB ratio; HR, hazard ratio; $95 \% \mathrm{Cl}, 95 \%$ confidence interval.

\section{Declarations}

\section{Acknowledgements}

Not applicable

\section{Authors' contributions}

CFZ, QZ and XJZ analyzed and interpreted the patient data regarding the peritoneal dialysis patients. $\mathrm{CFZ}, \mathrm{QZ}$ and $\mathrm{XQD}$ were the major contributors in writing the manuscript. YBC and $\mathrm{XJZ}$ made revision to the manuscript. All authors read and approved the final manuscript.

\section{Funding}

This study was supported by the Natural Science Foundation of Jiangxi Province, China (20212BAB216020) and the Project of Administration of Traditional Chinese Medicine of Jiangxi Province of China (2020Z020). 


\section{Availability of data and materials}

All datasets about this study available from the corresponding author.

\section{Ethics approval and consent to participate}

This study was approved by the Human Ethics Committee of Nanchang University (Application ID: [2021] 9-028).

\section{Consent for publication}

Not applicable.

\section{Competing interests}

The authors have declared that no competing interests exist.

\section{References}

1. Cho Y, Bello A, Levin A, Lunney M, Osman M, Ye F, et al. Peritoneal Dialysis Use and Practice Patterns: An International Survey Study. Am J Kidney Dis. 2021; 77:315-25. https://doi.org/10.1053/j.ajkd.2020.05.032.

2. Himmelfarb J, Vanholder R, Mehrotra R,Tonelli M. The current and future landscape of dialysis. Nat Rev Nephrol. 2020; 16:573-85.https://doi.org/10.1038/s41581-020-0315-4.

3. System USRD: 2020 USRDS Annual Data Report: Epidemiology of kidney disease in the United States. National Institutes of Health, National Institute of Diabetes and Digestive and Kidney Diseases, Bethesda, MD.

4. Fenton SS, Schaubel DE, Desmeules M, Morrison HI, Mao Y, Copleston P, et al. Hemodialysis versus peritoneal dialysis: a comparison of adjusted mortality rates. Am J Kidney Dis. 1997; 30:33442.https://doi.org/10.1016/s0272-6386(97)90276-6.

5. Vonesh EF, Snyder JJ, Foley RN,Collins AJ. The differential impact of risk factors on mortality in hemodialysis and peritoneal dialysis. Kidney Int. 2004; 66:2389-401.https://doi.org/10.1111/j.15231755.2004.66028.x.

6. Kendrick J,Teitelbaum I. Strategies for improving long-term survival in peritoneal dialysis patients. Clin J Am Soc Nephrol. 2010; 5:1123-31.https://doi.org/10.2215/CJN.04300709.

7. Cai K, Luo Q, Zhu B, Han L, Wu D, Dai Z, et al. Neutrophil-lymphocyte ratio is associated with arterial stiffness in patients with peritoneal dialysis. BMC Nephrol. 2016; 
17:191.https://doi.org/10.1186/s12882-016-0394-4.

8. Kaysen G. Hyperlipidemia of chronic renal failure. Blood Purif. 1994; 12:607.https://doi.org/10.1159/000170146.

9. Yusuf S, Hawken S, Ôunpuu S, Dans T, Avezum A, Lanas F, et al. Effect of potentially modifiable risk factors associated with myocardial infarction in 52 countries (the INTERHEART study): case-control study. Lancet. 2004; 364:937-52.https://doi.org/10.1016/s0140-6736(04)17018-9.

10. Wolska A,Remaley AT. Measuring LDL-cholesterol: what is the best way to do it? Curr Opin Cardiol. 2020; 35:405-11.https://doi.org/10.1097/HCO.0000000000000740.

11. Boren J, Chapman MJ, Krauss RM, Packard CJ, Bentzon JF, Binder CJ, et al. Low-density lipoproteins cause atherosclerotic cardiovascular disease: pathophysiological, genetic, and therapeutic insights: a consensus statement from the European Atherosclerosis Society Consensus Panel. Eur Heart J. 2020; 41:2313-30.https://doi.org/10.1093/eurheartj/ehz962.

12. Zhao W, Zheng XL, Jiang ZN, Liao XB,Zhao SP. Risk factors associated with atherogenic dyslipidemia in the presence of optimal statin therapy. Int J Cardiol. 2017; 248:35560.https://doi.org/10.1016/j.ijcard.2017.06.105.

13. Hirano $T$, Ito $Y$,Yoshino G. Measurement of small dense low-density lipoprotein particles. J Atheroscler Thromb. 2005; 12:67-72.https://doi.org/10.5551/jat.12.67.

14. Navarese EP, Robinson JG, Kowalewski M, Kolodziejczak M, Andreotti F, Bliden K, et al. Association Between Baseline LDL-C Level and Total and Cardiovascular Mortality After LDL-C Lowering: A Systematic Review and Meta-analysis. JAMA. 2018; 319:156679.https://doi.org/10.1001/jama.2018.2525.

15. Ye H, Wu H, Peng Y, Zhou Q, Cao P, Guo Q, et al. Peritonitis Affects the Relationship Between LowDensity Lipoprotein Cholesterol and Cardiovascular Events in Peritoneal Dialysis Patients. Can J Cardiol. 2020; 36:92-99.https://doi.org/10.1016/j.cjca.2019.08.028.

16. Prichard SS. Impact of dyslipidemia in end-stage renal disease. J Am Soc Nephrol. 2003; 14:S31520.https://doi.org/10.1097/01.asn.0000081698.10331.83.

17. Moberly J, Attman P, Samuelsson O, Johansson A, Knight-Gibson C,Alaupovic P. Alterations in lipoprotein composition in peritoneal dialysis patients. Perit Dial Int. 2002; 22:220-8.

18. Andrikoula $\mathrm{M}, \mathrm{McD}$ owell IF. The contribution of $\mathrm{ApoB}$ and $\mathrm{ApoA} 1$ measurements to cardiovascular risk assessment. Diabetes Obes Metab. 2008; 10:271-8.https://doi.org/10.1111/j.14631326.2007.00714.x.

19. Tani S, Saito Y, Anazawa T, Kawamata H, Furuya S, Takahashi H, et al. Low-density lipoprotein cholesterol/apolipoprotein B ratio may be a useful index that differs in statin-treated patients with and without coronary artery disease: a case control study. Int Heart J. 2011; 52:3437.https://doi.org/10.1536/ihj.52.343.

20. Drexel H, Larcher B, Mader A, Vonbank A, Heinzle C, Moser B, et al. The LDL-C/ApoB ratio predicts major cardiovascular events in patients with established atherosclerotic cardiovascular disease. Atherosclerosis. 2021; 329:44-49.https://doi.org/10.1016/j.atherosclerosis.2021.05.010. 
21. Kwon CH, Kim BJ, Kim BS,Kang JH. Low-density lipoprotein cholesterol to apolipoprotein B ratio is independently associated with metabolic syndrome in Korean men. Metabolism. 2011; 60:113641.https://doi.org/10.1016/j.metabol.2010.12.007.

22. Akutsu N, Hori K, Mizobuchi S, Ogaku A, Koyama Y, Fujito H, et al. Clinical Importance of the LDLC/Apolipoprotein B Ratio for Neointimal Formation after Everolimus-Eluting Stent Implantations. J Atheroscler Thromb. 2021.https://doi.org/10.5551/jat.60954.

23. Rabizadeh S, Rajab A, Mechanick JI, Moosaie F, Rahimi Y, Nakhjavani M, et al. LDL/apo B ratio predict coronary heart disease in Type 2 diabetes independent of ASCVD risk score: A case-cohort study. Nutr Metab Cardiovasc Dis. 2021; 31:1477-85.https://doi.org/10.1016/j.numecd.2021.01.013.

24. Camp R, Dolled-Filhart M,Rimm D. X-tile: a new bio-informatics tool for biomarker assessment and outcome-based cut-point optimization. Clin Cancer Res. 2004; 10:7252-

9.https://doi.org/10.1158/1078-0432.Ccr-04-0713.

25. Zhan X, Chen Y, Yan C, Liu S, Deng L, Yang Y, et al. Apolipoprotein B/apolipoprotein A1 ratio and mortality among incident peritoneal dialysis patients. Lipids Health Dis. 2018;

17:117.https://doi.org/10.1186/s12944-018-0771-z.

26. Martin SS, Blaha MJ, Elshazly MB, Toth PP, Kwiterovich PO, Blumenthal RS, et al. Comparison of a novel method vs the Friedewald equation for estimating low-density lipoprotein cholesterol levels from the standard lipid profile. JAMA. 2013; 310:2061-8.https://doi.org/10.1001/jama.2013.280532.

27. Wheeler DC, London GM, Parfrey PS, Block GA, Correa-Rotter R, Dehmel B, et al. Effects of cinacalcet on atherosclerotic and nonatherosclerotic cardiovascular events in patients receiving hemodialysis: the EValuation Of Cinacalcet $\mathrm{HCl}$ Therapy to Lower CardioVascular Events (EVOLVE) trial. J Am Heart Assoc. 2014; 3:e001363.https://doi.org/10.1161/JAHA.114.001363.

28. Johnson DW, Dent H, Hawley CM, McDonald SP, Rosman JB, Brown FG, et al. Association of dialysis modality and cardiovascular mortality in incident dialysis patients. Clin J Am Soc Nephrol. 2009; 4:1620-8.https://doi.org/10.2215/cjn.01750309.

29. Bagdade JD, Porte D, Jr.,Bierman EL. Hypertriglyceridemia. A metabolic consequence of chronic renal failure. N Engl J Med. 1968; 279:181-5.https://doi.org/10.1056/nejm196807252790403.

30. Cattran DC, Fenton SS, Wilson DR,Steiner G. Defective triglyceride removal in lipemia associated with peritoneal dialysis and haemodialysis. Ann Intern Med. 1976; 85:29-

33.https://doi.org/10.7326/0003-4819-85-1-29.

31. Kaysen GA. Lipid and lipoprotein metabolism in chronic kidney disease. J Ren Nutr. 2009; 19:737.https://doi.org/10.1053/j.jrn.2008.10.011.

32. Harper CR,Jacobson TA. Managing dyslipidemia in chronic kidney disease. J Am Coll Cardiol. 2008; 51:2375-84.https://doi.org/10.1016/j.jacc.2008.03.025.

33. Executive Summary of The Third Report of The National Cholesterol Education Program (NCEP) Expert Panel on Detection, Evaluation, And Treatment of High Blood Cholesterol In Adults (Adult Treatment Panel III). Jama. 2001; 285:2486-97.https://doi.org/10.1001/jama.285.19.2486. 
34. Baigent C, Landray MJ, Reith C, Emberson J, Wheeler DC, Tomson C, et al. The effects of lowering LDL cholesterol with simvastatin plus ezetimibe in patients with chronic kidney disease (Study of Heart and Renal Protection): a randomised placebo-controlled trial. Lancet. 2011;377:218192.https://doi.org/10.1016/s0140-6736(11)60739-3.

35. Baigent C, Blackwell L, Emberson J, Holland L, Reith C, Bhala N, et al. Efficacy and safety of more intensive lowering of LDL cholesterol: a meta-analysis of data from 170,000 participants in 26 randomised trials. Lancet. 2010; 376:1670-81.https://doi.org/10.1016/s0140-6736(10)61350-5.

36. Massy ZA, Ferrieres J, Bruckert E, Lange C, Liabeuf S, Velkovski-Rouyer M, et al. Achievement of LowDensity Lipoprotein Cholesterol Targets in CKD. Kidney Int Rep. 2019; 4:154654.https://doi.org/10.1016/j.ekir.2019.07.014.

37. Bajaj A, Xie D, Cedillo-Couvert E, Charleston J, Chen J, Deo R, et al. Lipids, Apolipoproteins, and Risk of Atherosclerotic Cardiovascular Disease in Persons With CKD. Am J Kidney Dis. 2019; 73:82736.https://doi.org/10.1053/j.ajkd.2018.11.010.

38. Wang B, Chen S, Liu J, Liang Y, Meng L, Yan X, et al. Association between baseline LDL-C and prognosis among patients with coronary artery disease and advanced kidney disease. BMC Nephrol. 2021; 22:168.https://doi.org/10.1186/s12882-021-02375-1.

39. Hager MR, Narla AD,Tannock LR. Dyslipidemia in patients with chronic kidney disease. Rev Endocr Metab Disord. 2017; 18:29-40.https://doi.org/10.1007/s11154-016-9402-z.

40. Boren J,Williams KJ. The central role of arterial retention of cholesterol-rich apolipoprotein-Bcontaining lipoproteins in the pathogenesis of atherosclerosis: a triumph of simplicity. Curr Opin Lipidol. 2016; 27:473-83.https://doi.org/10.1097/MOL.0000000000000330.

41. Ye M, Liu Y, Wang H, Tian N, Li W, He W, et al. Serum apolipoprotein B is inversely associated with eccentric left ventricular hypertrophy in peritoneal dialysis patients. Int Urol Nephrol. 2018; 50:15565.https://doi.org/10.1007/s11255-017-1737-1.

42. Steele J, Billington T, Janus E,Moran J. Lipids, lipoproteins and apolipoproteins A-I and B and apolipoprotein losses in continuous ambulatory peritoneal dialysis. Atherosclerosis. 1989; 79:4750.https://doi.org/10.1016/0021-9150(89)90032-4.

43. Sniderman AD, Thanassoulis G, Glavinovic T, Navar AM, Pencina M, Catapano A, et al. Apolipoprotein B Particles and Cardiovascular Disease: A Narrative Review. JAMA Cardiol. 2019; 4:128795.https://doi.org/10.1001/jamacardio.2019.3780.

44. Di Angelantonio E, Sarwar N, Perry P, Kaptoge S, Ray K, Thompson A, et al. Major lipids, apolipoproteins, and risk of vascular disease. JAMA. 2009; 302:19932000.https://doi.org/10.1001/jama.2009.1619.

45. Benn M, Nordestgaard B, Jensen G,Tybjaerg-Hansen A. Improving prediction of ischemic cardiovascular disease in the general population using apolipoprotein B: the Copenhagen City Heart Study. Arterioscler Thromb Vasc Biol. 2007; 27:66170.https://doi.org/10.1161/01.ATV.0000255580.73689.8e. 
46. Koch M, Kutkuhn B, Trenkwalder E, Bach D, Grabensee B, Dieplinger H, et al. Apolipoprotein B, fibrinogen, HDL cholesterol, and apolipoprotein(a) phenotypes predict coronary artery disease in hemodialysis patients. J Am Soc Nephrol. 1997; 8:1889-98.https://doi.org/10.1681/asn.V8121889.

47. Lamprea-Montealegre JA, Staplin N, Herrington WG, Haynes R, Emberson J, Baigent C, et al. Apolipoprotein B, Triglyceride-Rich Lipoproteins, and Risk of Cardiovascular Events in Persons with CKD. Clin J Am Soc Nephrol. 2020; 15:47-60.https://doi.org/10.2215/CJN.07320619.

48. Sato Y, Fujimoto S, Toida T, Nakagawa H, Yamashita Y, Iwakiri T, et al. Apoprotein B/Apoprotein A-1 Ratio and Mortality among Prevalent Dialysis Patients. Clin J Am Soc Nephrol. 2016; 11:8406.https://doi.org/10.2215/CJN.09830915.

49. Musunuru K. Atherogenic dyslipidemia: cardiovascular risk and dietary intervention. Lipids. 2010; 45:907-14.https://doi.org/10.1007/s11745-010-3408-1.

50. Yoshida A, Kouwaki M, Matsutani Y, Fukuchi Y,Naito M. Usefulness of serum total cholesterol/triglyceride ratio for predicting the presence of small, dense LDL. J Atheroscler Thromb. 2004; 11:215-9.https://doi.org/10.5551/jat.11.215.

51. Berneis KK,Krauss RM. Metabolic origins and clinical significance of LDL heterogeneity. J Lipid Res. 2002; 43:1363-79.https://doi.org/10.1194/jlr.r200004-jlr200.

52. Mikhailidis DP, Elisaf M, Rizzo M, Berneis K, Griffin B, Zambon A, et al. "European panel on low density lipoprotein (LDL) subclasses": a statement on the pathophysiology, atherogenicity and clinical significance of LDL subclasses. Curr Vasc Pharmacol. 2011; 9:533-

71.https://doi.org/10.2174/157016111796642661.

53. Rizzo M,Mikhailidis DP. There is more to predicting vascular disease than just established risk factors. Curr Pharm Des. 2011; 17:3608-10.https://doi.org/10.2174/138161211798220990.

54. St-Pierre AC, Cantin B, Dagenais GR, Mauriege P, Bernard PM, Despres JP, et al. Low-density lipoprotein subfractions and the long-term risk of ischemic heart disease in men: 13-year follow-up data from the Quebec Cardiovascular Study. Arterioscler Thromb Vasc Biol. 2005; 25:5539.https://doi.org/10.1161/01.ATV.0000154144.73236.f4.

55. Bowden RG, Wilson RL,Beaujean AA. LDL particle size and number compared with LDL cholesterol and risk categorization in end-stage renal disease patients. J Nephrol. 2011; 24:7717.https://doi.org/10.5301/JN.2011.6376.

56. Wägner A, Jorba O, Rigla M, Alonso E, Ordóñez-Llanos J,Pérez A. LDL-cholesterol/apolipoprotein B ratio is a good predictor of LDL phenotype B in type 2 diabetes. Acta diabetologica. 2002; 39:21520.https://doi.org/10.1007/s005920200037.

57. Sniderman A, St-Pierre A, Cantin B, Dagenais G, Després J,Lamarche B. Concordance/discordance between plasma apolipoprotein $B$ levels and the cholesterol indexes of atherosclerotic risk. Am J Cardiol. 2003; 91:1173-7.https://doi.org/10.1016/s0002-9149(03)00262-5.

58. Jungner I, Sniderman A, Furberg C, Aastveit A, Holme I,Walldius G. Does low-density lipoprotein size add to atherogenic particle number in predicting the risk of fatal myocardial infarction? Am $\mathrm{J}$ Cardiol. 2006; 97:943-6.https://doi.org/10.1016/j.amjcard.2005.10.062. 
59. Kaneva AM, Potolitsyna NN,Bojko ER. Usefulness of the LDL-C/apoB ratio in the overall evaluation of atherogenicity of lipid profile. Arch Physiol Biochem. 2017; 123:16-

22.https://doi.org/10.1080/13813455.2016.1195411.

60. Tani S, Yagi T, Atsumi W, Kawauchi K, Matsuo R,Hirayama A. Relation between low-density lipoprotein cholesterol/apolipoprotein B ratio and triglyceride-rich lipoproteins in patients with coronary artery disease and type 2 diabetes mellitus: a cross-sectional study. Cardiovasc Diabetol. 2017; 16:123.https://doi.org/10.1186/s12933-017-0606-7.

61. Bae JC, Han JM, Kwon S, Jee JH, Yu TY, Lee MK, et al. LDL-C/apoB and HDL-C/apoA-1 ratios predict incident chronic kidney disease in a large apparently healthy cohort. Atherosclerosis. 2016; 251:17076.https://doi.org/10.1016/j.atherosclerosis.2016.06.029.

62. Lamarche B, Lemieux I,Després JP. The small, dense LDL phenotype and the risk of coronary heart disease: epidemiology, patho-physiology and therapeutic aspects. Diabetes Metab. 1999; 25:199211.

63. Leroux G, Lemieux I, Lamarche B, Cantin B, Dagenais G, Lupien P, et al. Influence of triglyceride concentration on the relationship between lipoprotein cholesterol and apolipoprotein B and A-I levels. Metabolism. 2000; 49:53-61.https://doi.org/10.1016/s0026-0495(00)90688-7.

\section{Tables}

\section{Table 1}

\section{Characteristics of subjects stratified by LDL-C to Apo B ratio.}




\begin{tabular}{|c|c|c|c|c|}
\hline \multirow[t]{2}{*}{ Variables } & \multirow{2}{*}{$\begin{array}{l}\text { Total } \\
(n=1199)\end{array}$} & \multicolumn{2}{|c|}{ LDL-C to Apo B Ratio } & \multirow[t]{2}{*}{$P$ Value } \\
\hline & & $<1.04(n=419)$ & $\geq 1.04(n=780)$ & \\
\hline Age (yr) & $49.3 \pm 14.5$ & $51.1 \pm 14.3$ & $48.4 \pm 14.6$ & 0.002 \\
\hline Men (\%) & $696(58.0)$ & $262(62.5)$ & $434(55.6)$ & 0.021 \\
\hline $\mathrm{BMI}\left(\mathrm{kg} / \mathrm{m}^{2}\right)$ & $22.0 \pm 3.3$ & $22.1 \pm 3.4$ & $21.7 \pm 3.2$ & 0.053 \\
\hline $\mathrm{CCl}$ & $2.74 \pm 1.10$ & $2.78 \pm 1.14$ & $2.73 \pm 1.08$ & 0.454 \\
\hline Diabetes (\%) & $225(18.8)$ & $73(17.5)$ & $152(19.5)$ & 0.408 \\
\hline Hypertension (\%) & $898(75.1)$ & $292(70.2)$ & $606(77.8)$ & 0.004 \\
\hline CVD (\%) & $117(9.8)$ & $53(12.8)$ & $64(8.2)$ & 0.012 \\
\hline eGFR $\left(\mathrm{ml} / \mathrm{min}\right.$ per $\left.1.73 \mathrm{~m}^{2}\right)$ & $3.31(1.83,5.62)$ & $3.51(1.90,6.14)$ & $3.19(1.78,5.52)$ & 0.131 \\
\hline Hemoglobin $(g / L)$ & $80 \pm 17$ & $79 \pm 18$ & $80 \pm 17$ & 0.173 \\
\hline Albumin $(g / L)$ & $35.6 \pm 5.1$ & $35.2 \pm 4.9$ & $35.8 \pm 5.2$ & 0.049 \\
\hline Total cholesterol (mmol/L) & $4.07(3.37,4.85)$ & $3.64(3.08,4.30)$ & $4.32(3.60,5.04)$ & $<0.001$ \\
\hline Triglyceride (mmol/L) & $1.29(0.92,1.80)$ & $1.38(0.94,1.96)$ & $1.27(0.89,1.74)$ & 0.003 \\
\hline HDL-C (mmol/L) & $1.09(0.90,1.37)$ & $0.98(0.79,1.27)$ & $1.16(0.96,1.44)$ & $<0.001$ \\
\hline LDL-C (mg/dL) & $89.7(71.1,113.7)$ & $75.4(57.6,93.9)$ & $98.8(79.6,123.7)$ & $<0.001$ \\
\hline ApoB (mg/dL) & $80(64,100)$ & $86(70,110)$ & $78(62,98)$ & $<0.001$ \\
\hline Phosphorus (mmol/L) & $1.84 \pm 0.50$ & $1.83 \pm 0.53$ & $1.85 \pm 0.48$ & 0.546 \\
\hline iPTH (pg/ml) & $241(145,390)$ & $238(123,405)$ & $243(151,389)$ & 0.441 \\
\hline Ferritin $(\mu \mathrm{g} / \mathrm{L})$ & $202(96,398)$ & $222(109,433)$ & $189(91,377)$ & 0.012 \\
\hline
\end{tabular}

Abbreviations: LDL-C, low-density lipoprotein cholesterol; ApoB, apolipoprotein B; BMI, body mass index; $\mathrm{CCl}$, Charlson Comorbidity Index; eGFR, estimated glomerular filtration rate; CVD, cardiovascular disease; HDL-C, high-density lipoprotein cholesterol; iPTH, intact parathyroid hormone. P $<0.05$ was considered statistically significant.

\section{Table 2.}

Associations of LDL-C, ApoB, and LAR with all-cause mortality and cardiovascular events. 


\begin{tabular}{|c|c|c|c|c|c|c|}
\hline \multirow[t]{2}{*}{ Variables } & \multicolumn{2}{|l|}{ LDL-C } & \multicolumn{2}{|l|}{ ApoB } & \multicolumn{2}{|l|}{$\operatorname{LAR}^{d}$} \\
\hline & $\mathrm{HR}(95 \% \mathrm{Cl})$ & $\begin{array}{l}P \\
\text { Value }\end{array}$ & $\mathrm{HR}(95 \% \mathrm{Cl})$ & $\begin{array}{l}P \\
\text { Value }\end{array}$ & $\mathrm{HR}(95 \% \mathrm{Cl})$ & $\begin{array}{l}P \\
\text { Value }\end{array}$ \\
\hline \multicolumn{7}{|l|}{$\begin{array}{l}\text { All-cause } \\
\text { mortality }\end{array}$} \\
\hline Model $1^{\mathrm{a}}$ & $\begin{array}{l}1.00(1.00 \\
-1.01)\end{array}$ & 0.181 & $\begin{array}{l}1.01(1.00- \\
1.01)\end{array}$ & 0.003 & $\begin{array}{l}1.62(1.27- \\
2.07)\end{array}$ & $<0.001$ \\
\hline Model $2^{b}$ & $\begin{array}{l}1.00(1.00 \\
-1.01)\end{array}$ & 0.162 & $\begin{array}{l}1.01(1.00- \\
1.01)\end{array}$ & 0.012 & $\begin{array}{l}1.43(1.09- \\
1.89)\end{array}$ & 0.011 \\
\hline Model $3^{c}$ & $\begin{array}{l}1.00(1.00 \\
-1.01)\end{array}$ & 0.222 & $\begin{array}{l}1.01(1.00- \\
1.01)\end{array}$ & 0.060 & $\begin{array}{l}1.40(1.04- \\
1.87)\end{array}$ & 0.025 \\
\hline \multicolumn{7}{|c|}{$\begin{array}{l}\text { Cardiovascular } \\
\text { events }\end{array}$} \\
\hline Model $1^{a}$ & $\begin{array}{l}1.00(1.00- \\
1.00)\end{array}$ & 0.592 & $\begin{array}{l}1.00(1.00- \\
1.01)\end{array}$ & 0.403 & $\begin{array}{l}1.82(1.30- \\
2.55)\end{array}$ & $\begin{array}{l}< \\
0.001\end{array}$ \\
\hline Model $2^{b}$ & $\begin{array}{l}1.00(1.00- \\
1.01)\end{array}$ & 0.830 & $\begin{array}{l}1.00(1.00- \\
1.01)\end{array}$ & 0.481 & $\begin{array}{l}1.73(1.20- \\
2.48)\end{array}$ & 0.003 \\
\hline Model $3^{c}$ & $\begin{array}{l}1.00(1.00- \\
1.01)\end{array}$ & 0.769 & $\begin{array}{l}1.00(1.00- \\
1.01)\end{array}$ & 0.512 & $\begin{array}{l}1.62(1.11- \\
2.38)\end{array}$ & 0.013 \\
\hline \multicolumn{7}{|c|}{$\begin{array}{l}\text { Abbreviations: LDL-C, low-density lipoprotein cholesterol; ApoB, Apolipoprotein B; LAR, LDL-C to ApoB } \\
\text { ratio; HR, Hazard ratio; } 95 \% \mathrm{Cl}, 95 \% \text { confidence interval. } \\
\text { aModel 1: adjusted for age, sex, BMI, eGFR, CCI, diabetes, hypertension, premorbid cardiovascular } \\
\text { diseases. }\end{array}$} \\
\hline \multicolumn{7}{|c|}{$\begin{array}{l}{ }^{b} \text { Model 2: model } 1 \text { adjusted for hemoglobin, albumin, alkaline phosphatase, phosphorus, intact } \\
\text { parathyroid hormone and ferritin. }\end{array}$} \\
\hline \multicolumn{7}{|c|}{$\begin{array}{l}\text { cModel 3: model } 2 \text { adjusted for high-density lipoprotein cholesterol, triglyceride, and lipid-lowering } \\
\text { medication. }\end{array}$} \\
\hline${ }^{\mathrm{d}}$ LAR $\otimes 1.04$ & $R \geq 1.04$. & & & & & \\
\hline
\end{tabular}

\section{Figures}




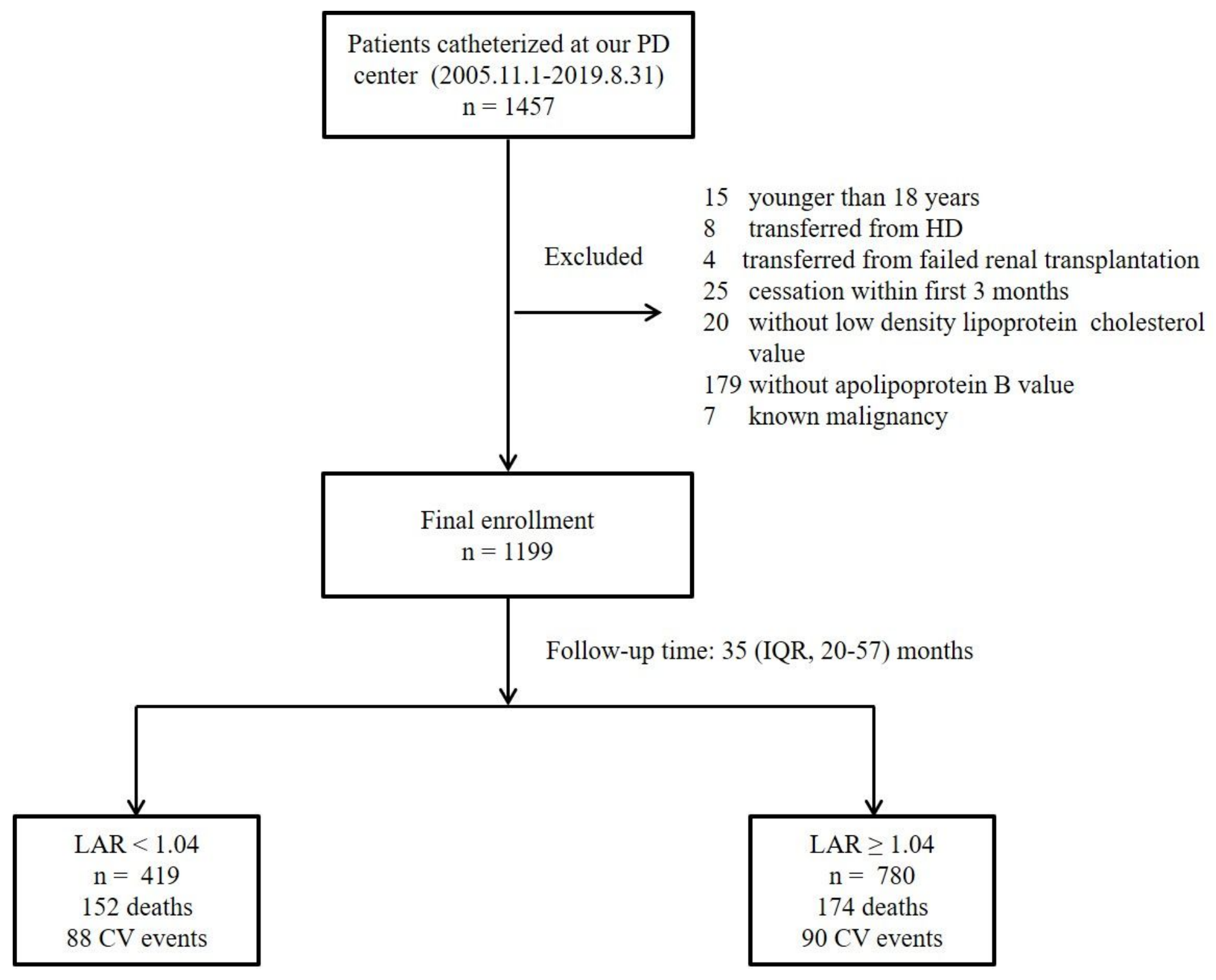

\section{Figure 1}

Enrollment flow chart. PD, peritoneal dialysis; HD, hemodialysis; LAR, Low-density lipoprotein cholesterol to apolipoprotein $B$ ratio; IQR, interquartile range; $C V$, cardiovascular. 

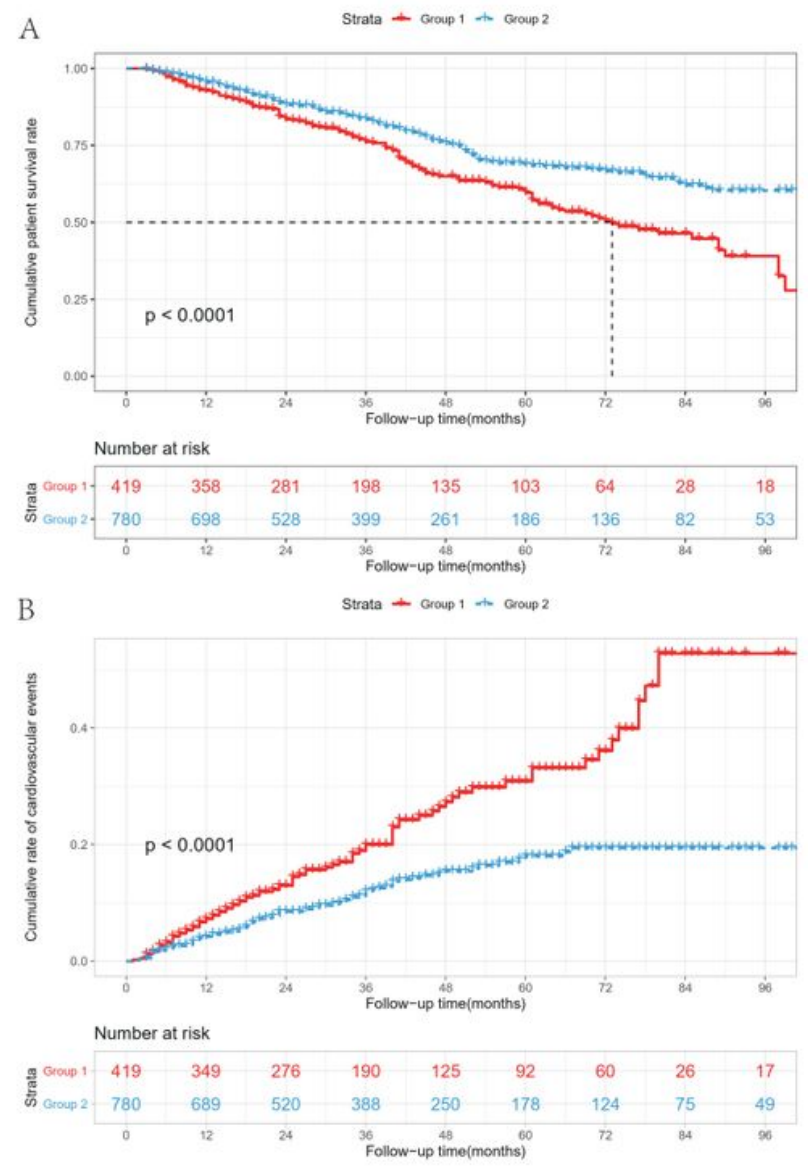

\section{Figure 2}

Survival curves of patients stratified by LAR. A. Cumulative patient survival rate. B. Cumulative rate of cardiovascular events. 

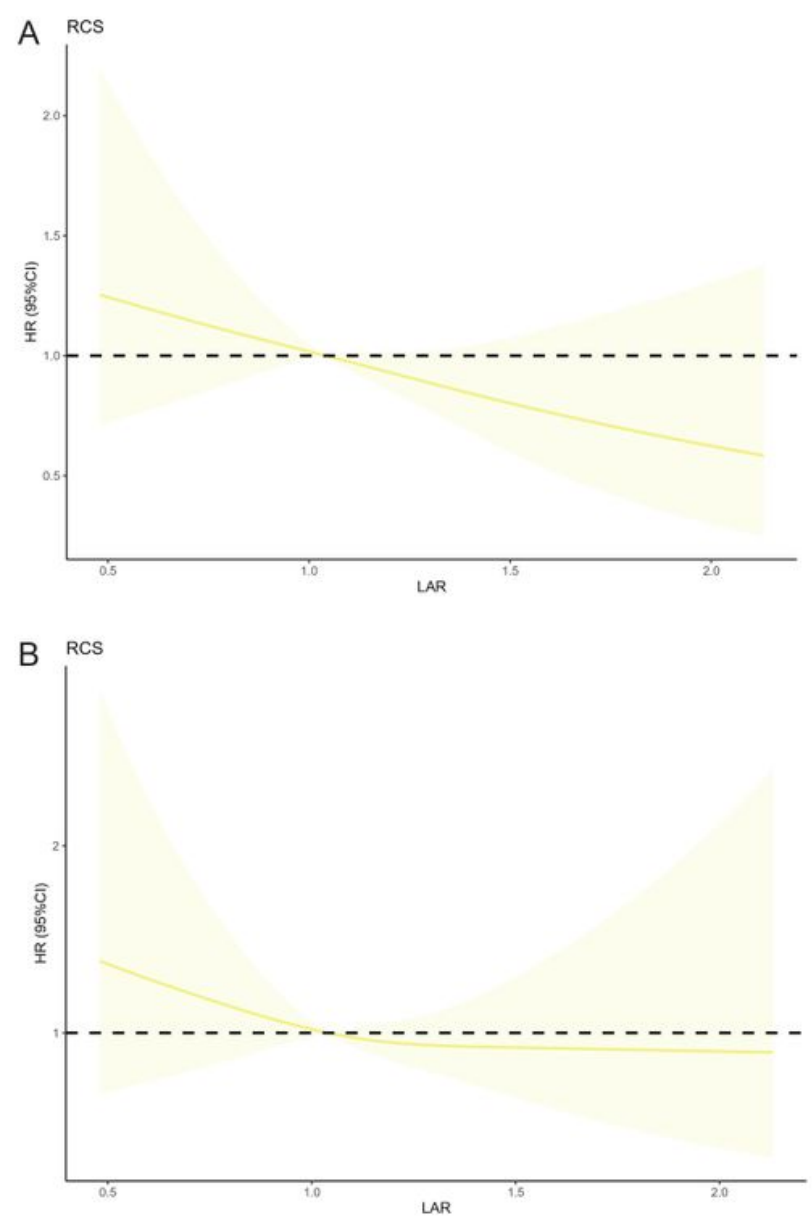

Figure 3

Restricted cubic spline regression model. A. All-cause mortality along with the changes in LAR. B. Cardiovascular events along with the changes in LAR. 